20

\title{
Спектральные проявления молекулярных механизмов образования наночастиц сульфида серебра методом бактериального синтеза
}

\author{
() И.Л. Пластун, А.А. Захаров, А.А. Наумов, П.А. Жулидин, П.Д. Филин \\ Саратовский государственный технический университет им. Ю.А. Гагарина, \\ 410054 Саратов, Россия \\ e-mail: inna_pls@mail.ru
}

Поступила в редакцию 05.01.2021 г.

В окончательной редакции 12.02.2021 г.

Принята к публикации 26.02.2021 г.

\begin{abstract}
Одним из перспективных для биофотоники и медицины материалов, используемых для диагностики и таргетной терапии онкологических заболеваний, являются наночастицы сульфида серебра. Спектральные проявления молекулярных механизмов взаимодействия белковых структур с солями металлов в ходе бактериального синтеза этих наночастиц исследованы с помощью молекулярного моделирования методами теории функционала плотности. Особенностью получения наночастиц сульфида серебра методом биосинтеза с помощью бактерий Bacillus subtilis 168 является то, что единственным белком, участвующим в процессе синтеза и адсорбирующимся на поверхности частиц, является белок флагеллин. В качестве исследуемых объектов рассматривались соли - нитрат серебра и тиосульфат натрия, участвующие в процессе синтеза, а также нестандартная аминокислота метиллизин, входящая в состав флагеллина. Моделирование проводилось на основе расчета образующихся молекулярных структур и их ИК спектров при помощи программного комплекса Gaussian 09. В ходе анализа параметров образующихся водородных связей было обнаружено, что метиллизин образует достаточно устойчивые молекулярные комплексы с нитратом серебра и тиосульфатом натрия. Это говорит о существенной роли метиллизина в образовании биогенных наночастиц сульфида серебра и проясняет механизм его функционирования в составе флагеллина.
\end{abstract}

Ключевые слова: ИК спектры, наночастицы, биосинтез, сульфид серебра, флагеллин, метиллизин, молекулярное моделирование, водородные связи, теория функционала плотности.

DOI: $10.21883 / \mathrm{OS} .2021 .06 .50982 .1 \mathrm{k}-21$

\section{Введение}

Применение наночастиц для диагностики и таргетной терапии различных заболеваний в настоящее время является одним из наиболее интенсивно развивающихся направлений в биофизике и медицине $[1,2]$. В частности, существенно возрос интерес к процессу синтеза биогенных наночастиц сульфидов металлов, поскольку эти полимерные композиционные наноматериалы обладают уникальными оптическими и электрическими свойствами, позволяющими их использовать в различных областях [3]: в биофизике и медицине - как биометки и точки фотолюминесценции для визуализации in vivo органов и тканей, а также как средство адресной доставки лекарственных препаратов, а в наноэлектронике, оптоэлектронике и энергетике - в качестве сенсоров, датчиков, фотопроводников и ИК детекторов. Одним из наиболее доступных и распространенных материалов среди наночастиц халькогенидов металлов является наноструктурированный моноклинный сульфид серебpa $\mathrm{Ag}_{2} \mathrm{~S}$. Малый диаметр этих полупроводниковых наночастиц позволяет их использовать в качестве квантовых точек $[4,5]$, применяемых как для визуализации in vivo органов и тканей [5] при ранней диагностике онкологических заболеваний, так и для таргетной терапии и удержания лекарств в клетках [1].
Как правило, наночастицы сульфидов металлов получают химическими методами, однако эти методы высокозатратны и экологически опасны. Кроме того, химически синтезированные наночастицы менее биосовместимы, что существенно ограничивает их применение в биологических и медицинских системах. В последнее время большое внимание уделяется созданию частиц с органической оболочкой, что вызвано необходимостью закрепления на поверхности ядра специфических групп (органических лигандов), предотвращающих агломерацию и рост частиц, их окисление и обеспечивающих получение стабильных изолированных наночастиц. В отличие от наночастиц, образуемых химическими методами, биогенные наночастицы, полученные в водных раствоpax соответствующих солей в присутствии различных типов микроорганизмов, характеризуются наличием на их поверхности белковых молекул, состав которых определяется бактериальной культурой. В этом отношении биологические методы получения наночастиц имеют ряд преимуществ: не требуют больших затрат энергии, дорогих и токсичных химических веществ, экологически безопасны, обеспечивают прочную органическую оболочку наночастиц и стабильные размеры около $10 \mathrm{~nm}$. Таким образом, можно сказать, что наночастицы сульфида серебра, получаемые с помощью биосинтеза на основе различных бактериальных культур [6,7], обладают 

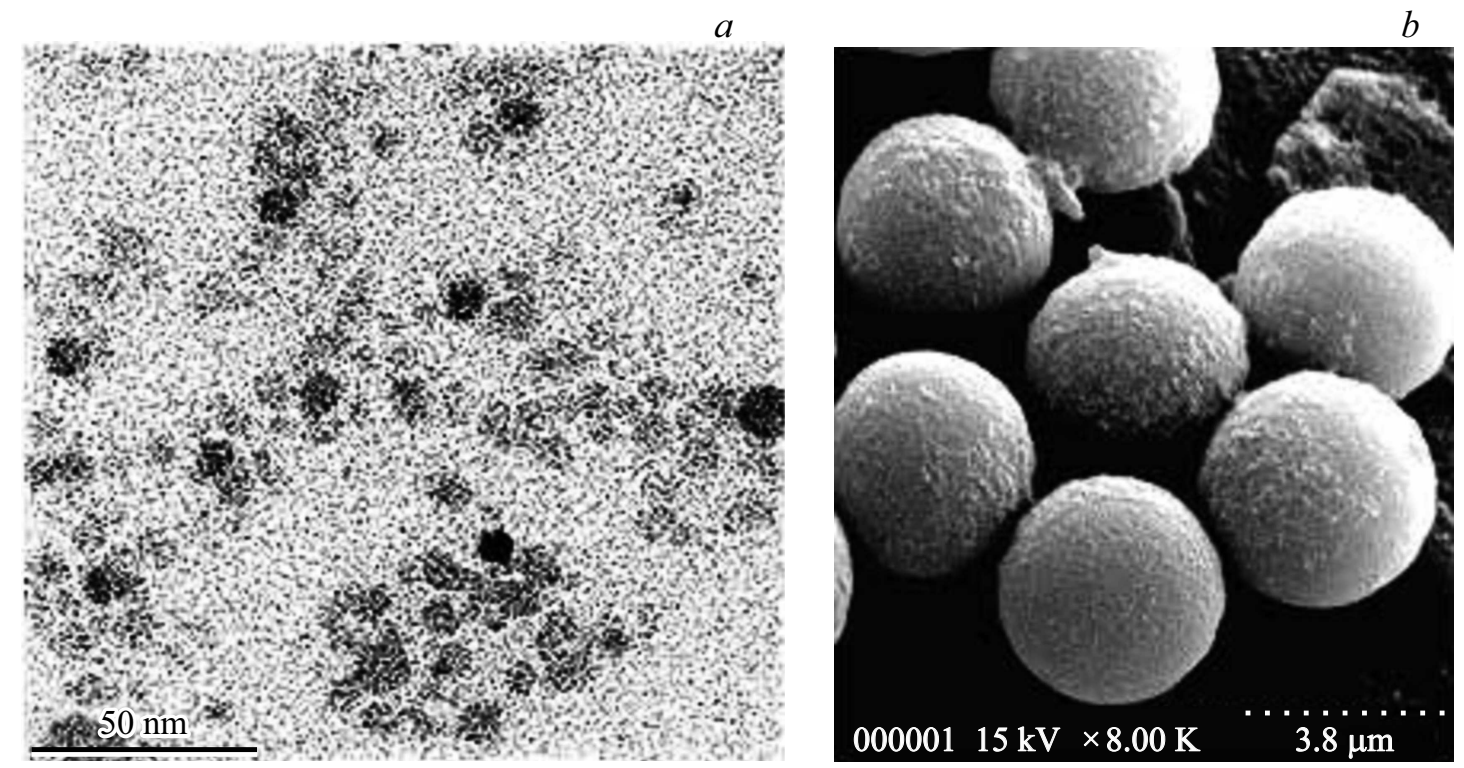

Рис. 1. Изображения наночастиц сульфида серебра $n p \mathrm{Ag}_{2} \mathrm{~S}$, синтезированных с помощью Bacillus subtilis 16, полученные в [6] с помощью электронной микроскопии: (a) ПЭМ-изображение с масштабной меткой $50 \mathrm{~nm} ;(b)$ изображения полистирольных микросфер, модифицированных $n p \mathrm{Ag}_{2} \mathrm{~S}$, полученные на сканирующем электронном микроскопе.

высокой степенью биосовместимости за счет белковой оболочки, а малый размер позволяет использовать их в биофизике и биомедицине как флуоресцентные метки для визуализации биопроцессов in vivo и как средство удержания лекарственных препаратов в клетках.

\section{Объекты исследования}

В работе исследованы механизмы межмолекулярного взаимодействия белковых структур с солями рабочего раствора, используемого для получения наночастиц сульфида серебра, а именно - с водными растворами солей нитрата серебра $\mathrm{AgNO}_{3}$ и тиосульфата натрия $\mathrm{Na}_{2} \mathrm{~S}_{2} \mathrm{O}_{3}$. В качестве исследуемого белка рассмотрен бактериальный белок флагеллин, поскольку, как показано в экспериментальном исследовании [7], при биосинтезе с помощью грамположительных бактерий Bacillus subtilis 168 (сенная палочка) только этот белок сорбируется на поверхности наночастиц сульфида серебра $\mathrm{Ag}_{2} \mathrm{~S}$ и, таким образом, является одной из важнейших составляющих процесса бактериального синтеза. На рис. 1 продемонстрированы полученные с помощью электронной микроскопии изображения наночастиц сульфида серебра $n p \mathrm{Ag}_{2} \mathrm{~S}$, синтезированных с помощью Bacillus subtilis 16 в работе [6]. Необходимо отметить, что в экспериментах по сравнительному анализу состава белковых оболочек наночастиц, полученных методами биосинтеза на основе грамположительных бактерий Bacillus subtilis 168 и грамотрицательных бактерий Shewanella oneidensis MR-1 и Escherichia coli K12 [7], наблюдалось сильное различие состава белковых оболочек наночастиц. Как отмечается в [7], у наночастиц, синтезированных на основе других бактерий, в составе оболочки флагеллина либо совсем не было, либо он присутствовал в числе многих белков оболочки, при этом размер оболочки был значительно меньше, чем при биосинтезе с помощью бактерий Bacillus subtilis 168 при размере наночастицы $\mathrm{Ag}_{2} \mathrm{~S} 8-10 \mathrm{~nm}$ во всех случаях. Таким образом, можно сделать вывод о существенной роли флагеллина в образовании белковой оболочки.

Флагеллин представляет собой белок, образующий нить жгутика бактерии [8], способный самоорганизовываться в полые цилиндрические структуры и являющийся лигандом для рецептора врожденной иммунной системы TLR5. Структура флагеллина с метилазой из состава Bacillus subtilis 168 из базы RCSB PDB [9] и полный состав аминокислот флагеллина, приведенный в [10], показаны на рис. 2, a. Необходимо отметить, что флагеллин у Bacillus subtilis 168, как показано в [9], присутствует вместе с метиллазой, которая представляет собой специальный модифицирующий фермент, с помощью которого бактерии метят свою ДНК для сохранения собственного генома путем метилирования азотистых оснований ДНК. Благодаря метилированию в состав флагеллина у многих бактерий входит нестандартная аминокислота метиллизин $\mathrm{C}_{7} \mathrm{H}_{16} \mathrm{O}_{2} \mathrm{~N}_{2}[8,10]$, которая, как и все нестандартные аминокислоты, является производной обычных аминокислот и включается в состав белков как во время их синтеза, так и в результате дополнительных ферментативных реакций.

Как отмечается в [8], синтез метиллизина происходит уже в составе молекулы флагеллина путем метилирования лизина $\mathrm{C}_{6} \mathrm{H}_{14} \mathrm{~N}_{2} \mathrm{O}_{2}$, т.е. замещения водорода метильной группой $-\mathrm{CH}_{3}$, при этом метилированные остатки лизина находятся на поверхности молекулы фла- 


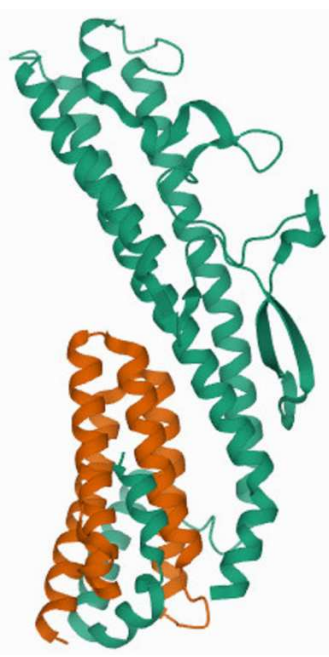

Met-Arg-Ile-Asn-His-Asn-Ile-Ala-Ala-Leu-Asn-Thr-Leu-Asn-Arg-Leu-Ser-Ser-Asn-Asn-Ser-Ala-Ser-Gln-Lys-

Ile-Ser-Asn-Arg -Thr-Glu- Phe-Asn-Gly-Lys-Lys-Leu-Leu-Asp-Gly-Thr-Pyr-Iys -Val-Asp-Thr-Ala-Thr-Fro-Ala- 150

Asn-Gln-Lys-Asn-Leu-Val-Phe-Gln-Ile-Gly-Ala-Asn-Ala-Thr-Gln-Gln-Ile-Ser-Val-Asn-Ile-Glu-Asp-Met-Gly- 175

Ala-ASp-Ala-Leu-Gly-Ile-Lys-Glu-Ala-Asp-Gly-Ser-Ile-Ala-Ala-Leu-His-Ser-Val-Asn-Asp-Ieu-Asp-Val-Thr- 200

Iys-Phe-Ala-Asp-Asn-Ala-Aia-Asp-Thr-Ala-Asp-Ile-Gly-Phe-Asp-Ala-Gln-Leu-Iys-Val-Val-Asp-Glu-Ala-Ile- 225

Asn-Gln-Val-Ser-Ser-Gln-Arg-Ala-Lys-Leu-Gly-Ala-Val-Gln-Asn-Arg-Leu-Glu-His-Thr-Ile-Asr-Asn-Leu-Ser- 250

Ala-Ser-Gly-Glu-Asn-Leu-Thr-Ala-Ala-Glu-Ser-Arg-Ile-Arg-Asp-Val-Asp-Met-Ala-Lys-Glu-Met-Ser-Glu-Phe- 275

Thr-Iys-Asn-Asn-Ile-Leu-Ser-Gln-Ala-Ser-Gln-Ala-Met-Leu-Ala-Gin-Ala-Asn-Gln-GIn-Pro-Gln-Asn-Val-Ieu- 300

GIn-Leน-Leu-Arg
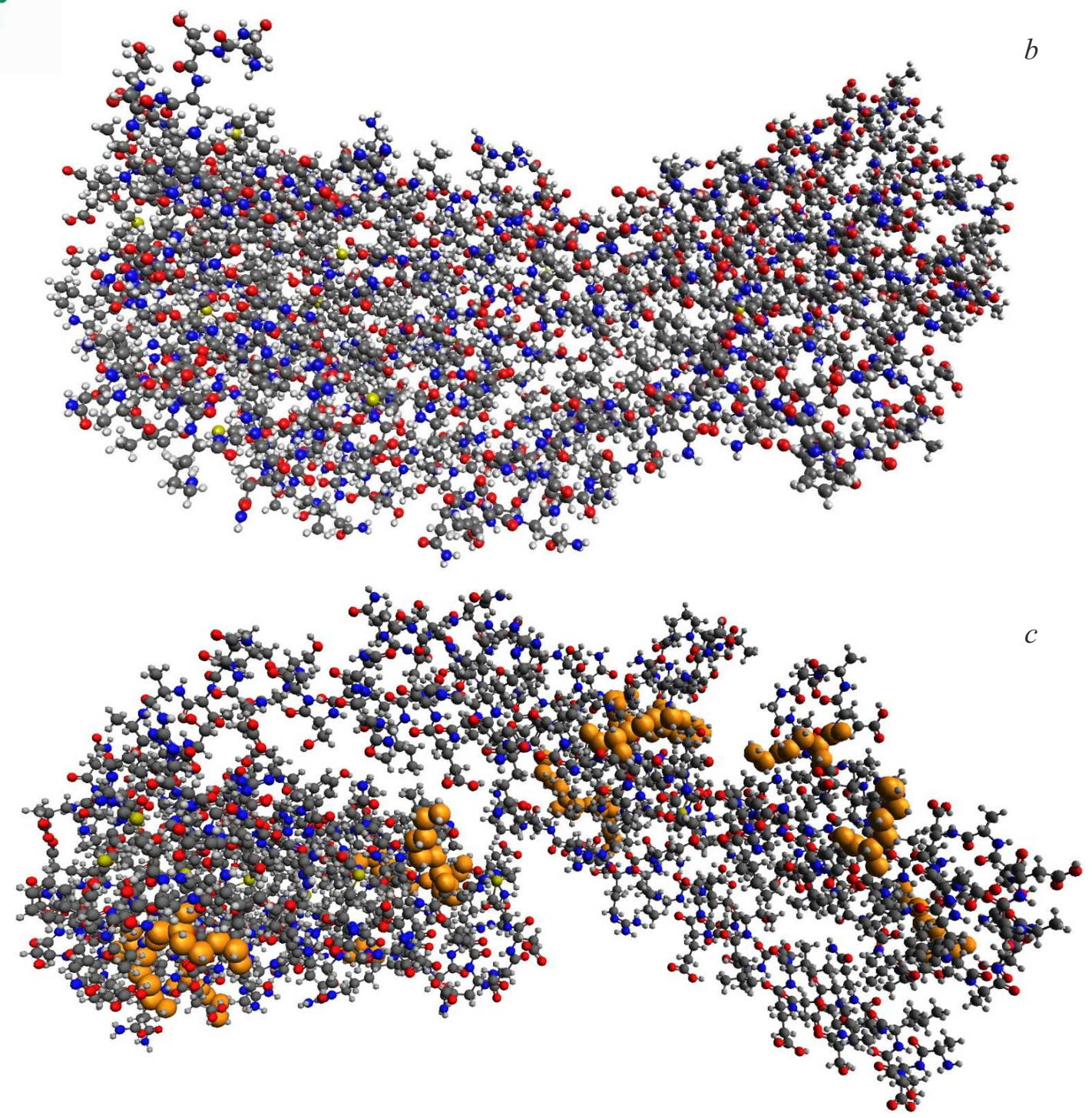

Рис. 2. Молекула флагеллина Bacillus subtilis 168: (a) структура флагеллина (зеленый) с метиллазой (оранжевый) [9] (слева) и полная последовательность аминокислот [10] (справа), (b) молекулярная структура, рассчитанная в Avogadro, где красным цветом отмечены атомы кислорода, синим - азота, темно-серым - углерода, серым - водорода; $(c)$ рассчитанная молекулярная структура с выделенным желтым лизином. 


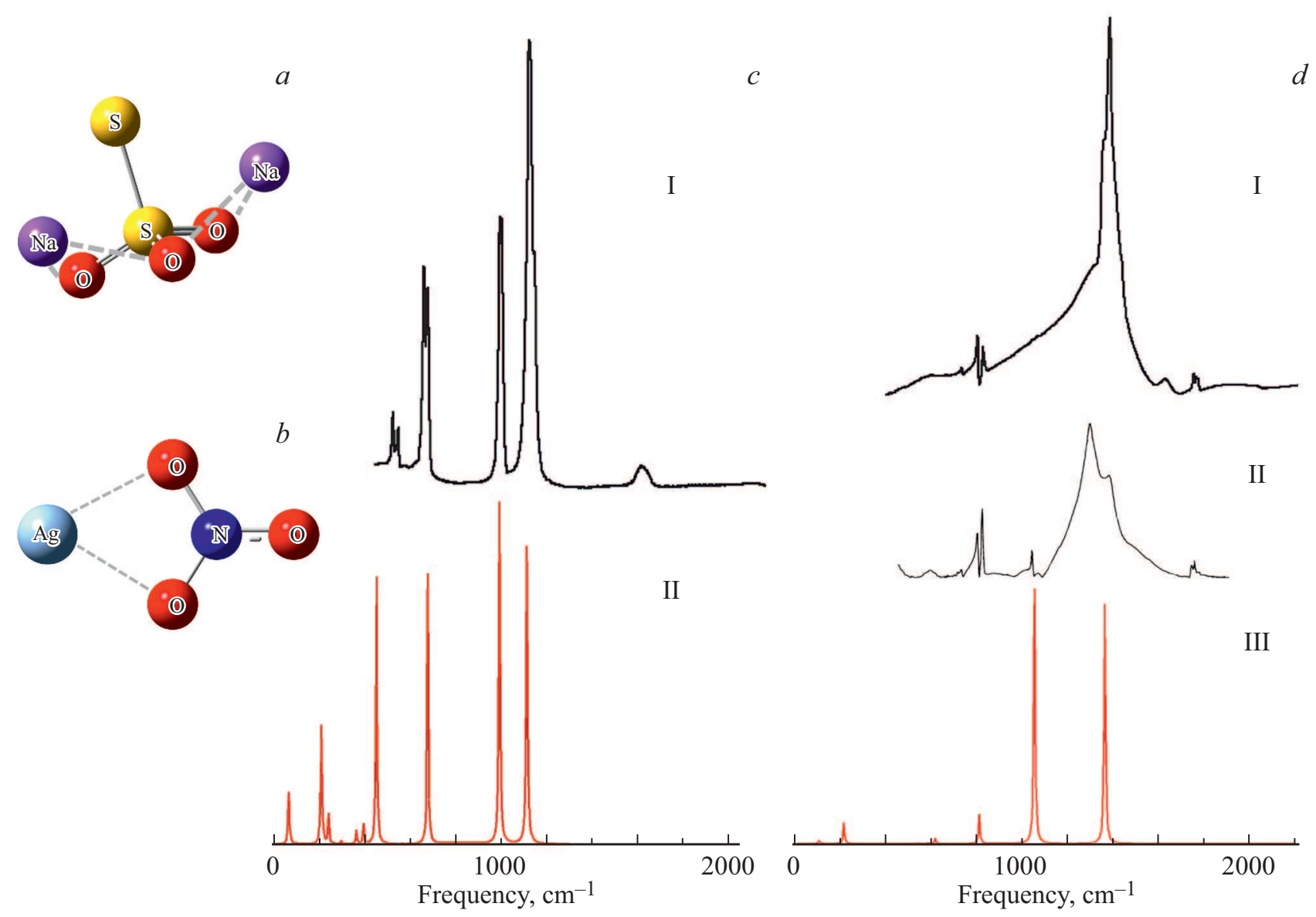

Рис. 3. Рассчитанные структуры $(a, b)$ и ИК спектры (c (II), $d$ (III)) молекул: $(a, c)$ тиосульфата натрия $\mathrm{Na}_{2} \mathrm{~S}_{2} \mathrm{O}_{3},(b, d)$ нитрата серебра $\mathrm{AgNO}_{3}$ и экспериментальные ИК спектры тиосульфата натрия (c (I)) и нитрата серебра $(d$ (I, II)), взятые из международной базы данных химических соединений и смесей PubChem $(c$ (I) $[17], d(\mathrm{I})[18])$ и работы [19] $(d$ (II)).

геллина. Биологический смысл образования лизиновых производных может заключаться в том, что молекула после метилирования становится более устойчивой к воздействию внешних факторов [8].

Кроме того, метиллизин присутствует в мышечном белке миозине, участвующем в работе сократительной системы [11]. Таким образом, можно сделать предположение, что метиллизин играет важную роль в образовании наночастиц, способствуя „скручивающему“ и „обволакивающему“ эффектам, чем обеспечивает более прочную и объемную белковую оболочку образующихся наночастиц, что наблюдалось экспериментально [7]. Однако данное предположение необходимо подтвердить на основе исследования межмолекулярного взаимодействия метиллизина с компонентами рабочего раствора.

Одним из методов оценки степени межмолекулярного взаимодействия, определяющего механизмы образования наночастиц, является исследование возможности комплексообразования метиллизина с солями тиосульфата натрия $\mathrm{Na}_{2} \mathrm{~S}_{2} \mathrm{O}_{3}$ и нитрата серебра $\mathrm{AgNO}_{3}$ на основе расчетов молекулярных структур и их ИК спектров с последующим анализом параметров образующихся в смеси водородных связей.
Ранее нами проводились подобные численные оценки для анализа степени межмолекулярного взаимодействия модифицированных наноалмазов с биомолекулами и лекарственными препаратами [12], где на основе рассмотрения фрагментов крупных молекулярных структур можно сделать вывод о степени комплексообразования. Хорошее совпадение с экспериментальными результатами дает возможность распространить данную методику и на другие задачи.

Моделирование структуры и расчет спектров молекул и их комплексов осуществлялись на основе анализа межмолекулярного взаимодействия методами теории функционала плотности (DFT) [13] с использованием функционала B3LYP [14], в котором применяется представление молекулярных орбиталей в виде линейной комбинации линейно независимых функций, называемых базисными. В качестве базисных функций в данной работе использовался гауссов тип функций в валентнорасщепленном базисном наборе. Такие базисы отличаются повышенной точностью, что достигается представлением валентных орбиталей двумя наборами функций. Валентно-расщепленные базисы обозначаются $M-N P G$, где $M$ обозначает количество простых гауссовых функ- 

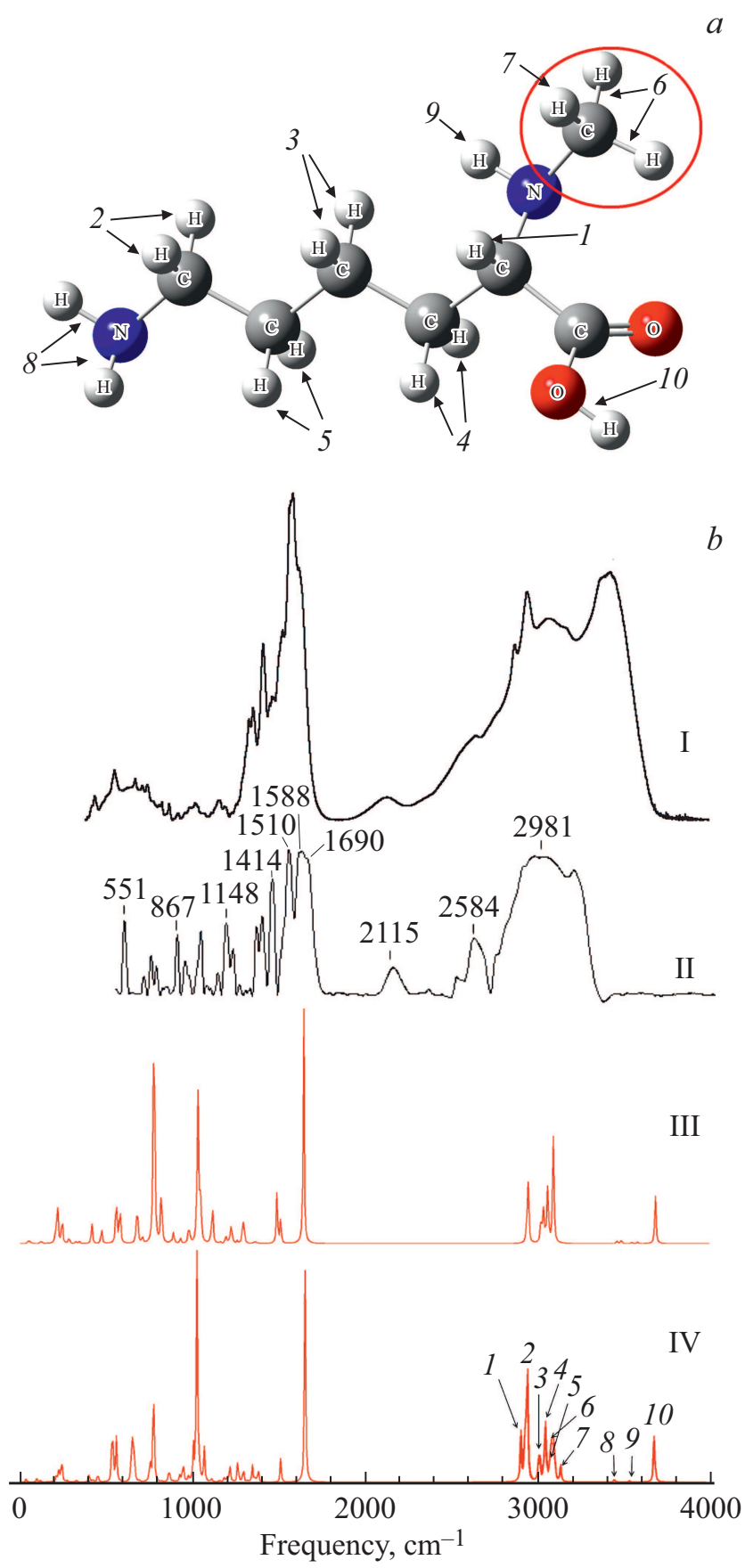

Рис. 4. Рассчитанные структура (a) и ИК спектры (b (III, IV) ) молекул: $(a, b(\mathrm{IV}))$ метиллизина $\mathrm{C}_{7} \mathrm{H}_{16} \mathrm{O}_{2} \mathrm{~N}_{2}$ с обозначенными валентными связями $(1-10)$, соответствующими им спектральными полосами и выделенной метильной группой $-\mathrm{CH}_{3}$ и экспериментальные ИК спектры лизина $\mathrm{C}_{6} \mathrm{H}_{14} \mathrm{~N}_{2} \mathrm{O}_{2}$ (b (I, II)), взятые из международной базы данных химических соединений и смесей PubChem $[20]$ (b (I)) и работы $[21](b(\mathrm{II}))$.

ций, входящих в состав базисной функции атомной орбитали, $N$ и $P$ показывают, что каждая валентная орбиталь состоит из двух базисных функций, первая из которых представляет собой линейную комбинацию $N$ простых гауссовых функций, а вторая $-P$ простых гауссовых функций [14]. В данной работе процедуры оптимизации геометрии молекулярных структур и расчет ИК спектров производились с использованием базисного набора 6-31G(d), в котором атомные орбитали электронов внутренней оболочки аппроксимируются шестью гауссовыми функциями $(M=6)$, а орбитали валентной оболочки описываются соответственно тремя $(N=3)$ и одной $(P=1)$ гауссовыми функциями с добавлением поляризационных компонент. Расчет структур, ИК спектров и молекулярных комплексов нитрата серебра $\mathrm{AgNO}_{3}$ проводился с использованием валентно-расщепленного базиса с эффективными потенциалами остова (effective core potentials - ECP) LANL2DZ [15], который используется в квантовой химии при изучении соединений или кластеров, содержащих тяжелые элементы.

Процедуры молекулярного моделирования были проведены с использованием программного комплекса Gaussian 09 [16] и визуализатора молекулярных структур Avogadro, широко применяемых для решения задач молекулярного моделирования в различных сферах вычислительной физики и химии.

Для учета ангармонизма во взаимодействии и соответственно снижения степени расхождения между экспериментальными и вычисленными данными нами были использованы масштабирующие множители для всех рассчитанных частот: 0.8742 (диапазон $0-1000 \mathrm{~cm}^{-1}$ ), 0.89 (диапазон 1000-2000 $\mathrm{cm}^{-1}$ ), 0.995 (диапазон свыше $\left.2000 \mathrm{~cm}^{-1}\right)$.

\section{Результаты и обсуждение}

В ходе вычислений были рассчитаны структура и ИК спектры молекул метиллизина, лизина, тиосульфата натрия $\mathrm{Na}_{2} \mathrm{~S}_{2} \mathrm{O}_{3}$ и нитрата серебра $\mathrm{AgNO}_{3}$, а также молекулярных комплексов метиллизина с каждой солью и с обеими солями одновременно.

Полная структура молекулы флагеллина из состава Bacillus subtilis 168 с обозначенным в его структуре лизином показана на рис. 2. Пространственную структуру флагеллина с метилазой [9] и состав аминокислот [10] можно видеть на рис. $2, a$, а рассчитанная и оптимизированная нами в программе Avogadro молекулярная структура флагеллина с отмеченным лизином представлена на рис. $2, b$.

На рис. 3 и 4 представлены рассчитанные структуры и ИК спектры, а также экспериментальные ИК спектры отдельных составляющих исследуемой молекулярной системы. В ИК спектрах тиосульфата натрия (рис. 3,c) и нитрата серебра (рис. $3, d$ ) хорошо видно соответствие спектральных полос экспериментальных и рассчитанных спектров в области средних частот: для тиосульфата натрия это область $500-1200 \mathrm{~cm}^{-1}$, а для нитрата серебра $-800-1600 \mathrm{~cm}^{-1}$.

Поскольку целью исследования является анализ параметров водородных связей как одной из основных 

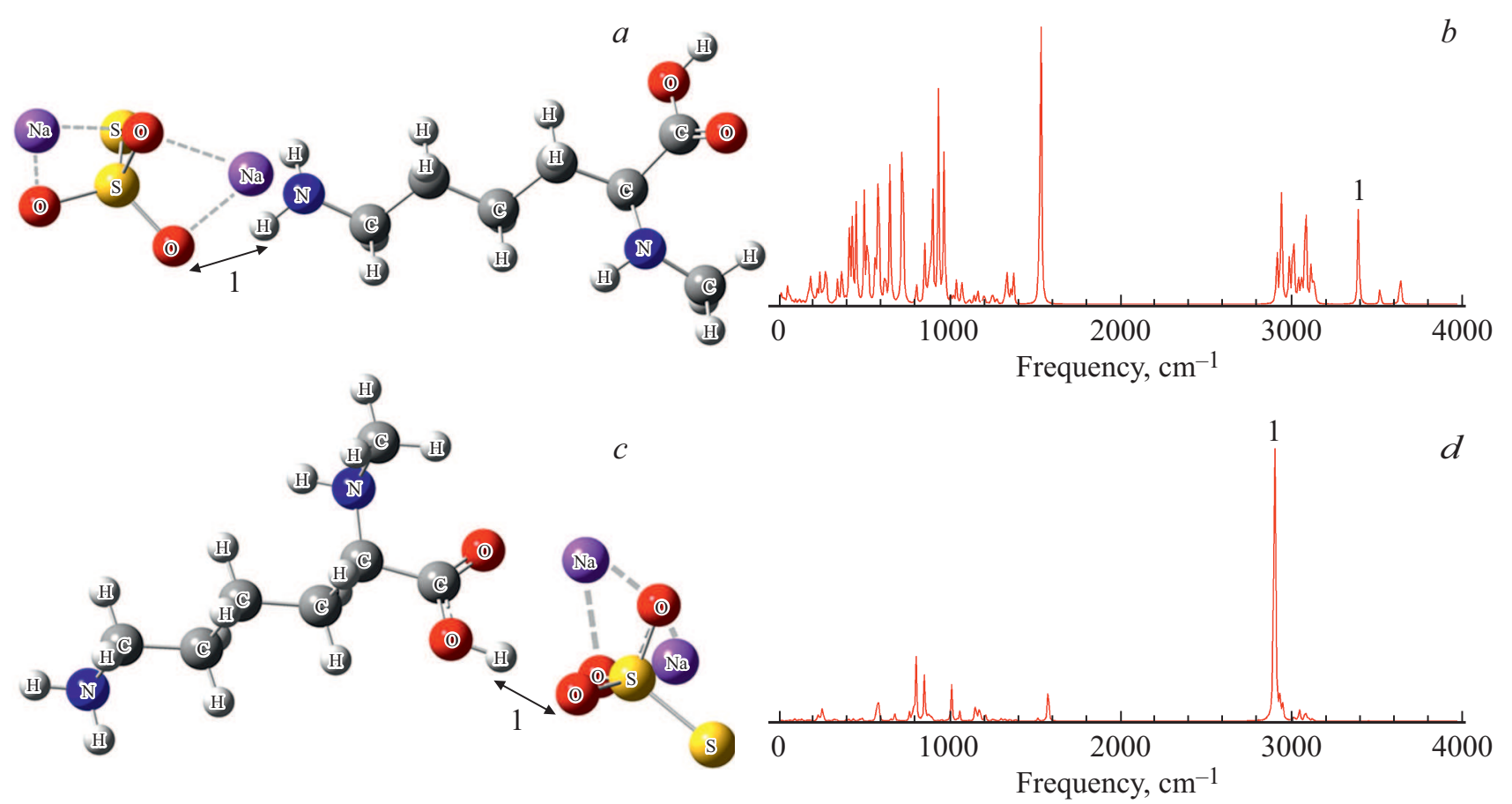

Рис. 5. Рассчитанные структуры $(a, c)$ и ИК спектры $(b, d)$ для двух различных вариантов $(1-a, b),(2-c, d)$ комплексообразования тиосульфата натрия $\mathrm{Na}_{2} \mathrm{~S}_{2} \mathrm{O}_{3}$ с метиллизином с обозначенными О $\cdots \mathrm{H}$ связями (1).

характеристик степени межмолекулярного взаимодействия и комплексообразования в многокомпонентных смесях [22,23], то основное внимание будем обращать на область ИК спектра от $2000 \mathrm{~cm}^{-1}$ и выше, где в спектре метиллизина хорошо заметны полосы (1-10 на рис. 4, $b(\mathrm{IV}))$, соответствующие валентным колебаниям связей $\mathrm{C}-\mathrm{H}(1-7), \mathrm{N}-\mathrm{H}(8,9)$ и $\mathrm{O}-\mathrm{H}(10)$. Частоты валентных колебаний связей составляют: $v_{1}=2897 \mathrm{~cm}^{-1}, \quad v_{2}=2937 \mathrm{~cm}^{-1}, \quad v_{3}=3000 \mathrm{~cm}^{-1}$, $v_{4}=3040 \mathrm{~cm}^{-1}, \quad v_{5}=3072 \mathrm{~cm}^{-1}, \quad v_{6}=3080 \mathrm{~cm}^{-1}$, $v_{7}=3128 \mathrm{~cm}^{-1}, \quad v_{8}=3518 \mathrm{~cm}^{-1}, \quad v_{9}=3526 \mathrm{~cm}^{-1}$, $v_{10}=3669 \mathrm{~cm}^{-1}$. Длина связей $R_{\mathrm{C}-\mathrm{H}}$ во всех случаях составляет $1.09 \AA$, длина связи $R_{\mathrm{O}-\mathrm{H}}=0.97 \AA$, а длина связей $R_{\mathrm{N}-\mathrm{H}}=1.01 \AA$. Полосы $1-5$ соответствуют валентным колебаниям внутренних связей $\mathrm{C}-\mathrm{H}$, не участвующих в процессе комплексообразования, а полосы 6 и 7 соответствуют антисимметричным и симметричным колебаниям трех связей $\mathrm{C}-\mathrm{H}$ метильной группы $-\mathrm{CH}_{3}$, появляющейся у лизина $\mathrm{C}_{6} \mathrm{H}_{14} \mathrm{~N}_{2} \mathrm{O}_{2}$ в результате метилирования (на рис. 4, $a$ эта группа выделена). Как видно из сравнения рассчитанных ИК спектров лизина и метиллизина (рис. $4, b$ (III, IV)), присоединение метильной группы не вносит существенных изменений в расположение спектральных полос в интересующей нас области спектра, где появляются только пики 6 и 7. Наибольшее участие в процессе комплексообразования принимают связи $\mathrm{N}-\mathrm{H}$ (пики 8,9) и $\mathrm{O}-\mathrm{H}$ (пик 10), смещение спектральных полос которых и будет отслеживаться в ходе последующего моделирования.
Структуры и ИК спектры образующихся молекулярных комплексов показаны на рис. 5-7.

Сила образовавшихся водородных связей оценивалась в соответствии с классификацией, приведенной в [24], где сильными водородными связями считаются связи с энергией $14.34-28.65 \mathrm{kkal} / \mathrm{mol}$ и длиной водородного мостика 2.2-2.5 в диапазоне $3.82-14.43 \mathrm{kkal} / \mathrm{mol}$, а длина водородного мостика 2.5-3.2 А, у слабых связей энергия менее $2.87 \mathrm{kkal} / \mathrm{mol}$, а длина водородного мостика 3.2-4.0 А.

В табл. 1-3 мы приводим следующие параметры связей: тип, $R, \AA-$ исходная длина Н-связи, $R_{b}, \AA-$ длина водородного мостика $\mathrm{N}-\mathrm{H} \cdots \mathrm{O}$ или $\mathrm{O}-\mathrm{H} \cdots \mathrm{O}$ (в зависимости от типа связи), $I_{\mathrm{IR}}, \mathrm{km} / \mathrm{mol}-$ интенсивность пика спектральной линии, $\Delta v, \mathrm{~cm}^{-1}-$ сдвиг частоты валентных колебаний Н-связей в ИК спектрах молекулярного комплекса относительно ИК спектра отдельных молекул, необходимая для расчета энергии связи $\Delta H, \mathrm{kcal} / \mathrm{mol}$, по эмпирической формуле Иогансена [22]:

$$
-\Delta H=0.3 \sqrt{\Delta v-40} .
$$

Были рассчитаны различные возможности комплексообразования солей с метиллизином. Как показали расчеты, и для тиосульфата натрия $\mathrm{Na}_{2} \mathrm{~S}_{2} \mathrm{O}_{3}$, и для нитрата серебра $\mathrm{AgNO}_{3}$ существуют несколько различных вариантов присоединения к метиллизину.

Рассчитанные структуры и ИК спектры для некоторых вариантов показаны на рис. 5 и 6, вычисленные параметры водородных связей для всех рассмотренных 

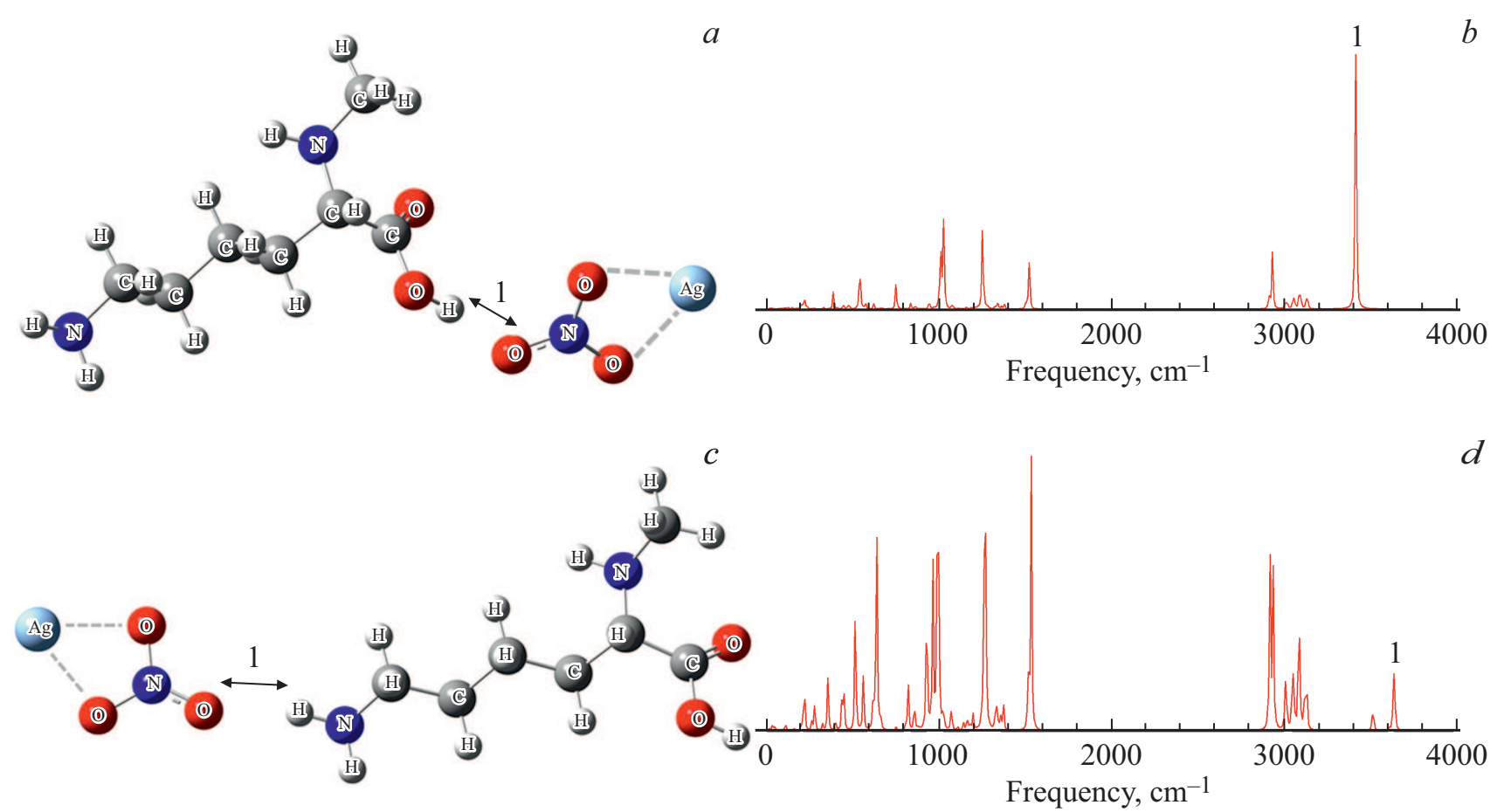

Рис. 6. Рассчитанные структуры $(a, c)$ и ИК спектры $(b, d)$ для двух различных вариантов $(1-a, b),(2-c, d)$ комплексообразования нитрата серебра $\mathrm{AgNO}_{3}$ с метиллизином с обозначенными О ... Н связями (1).
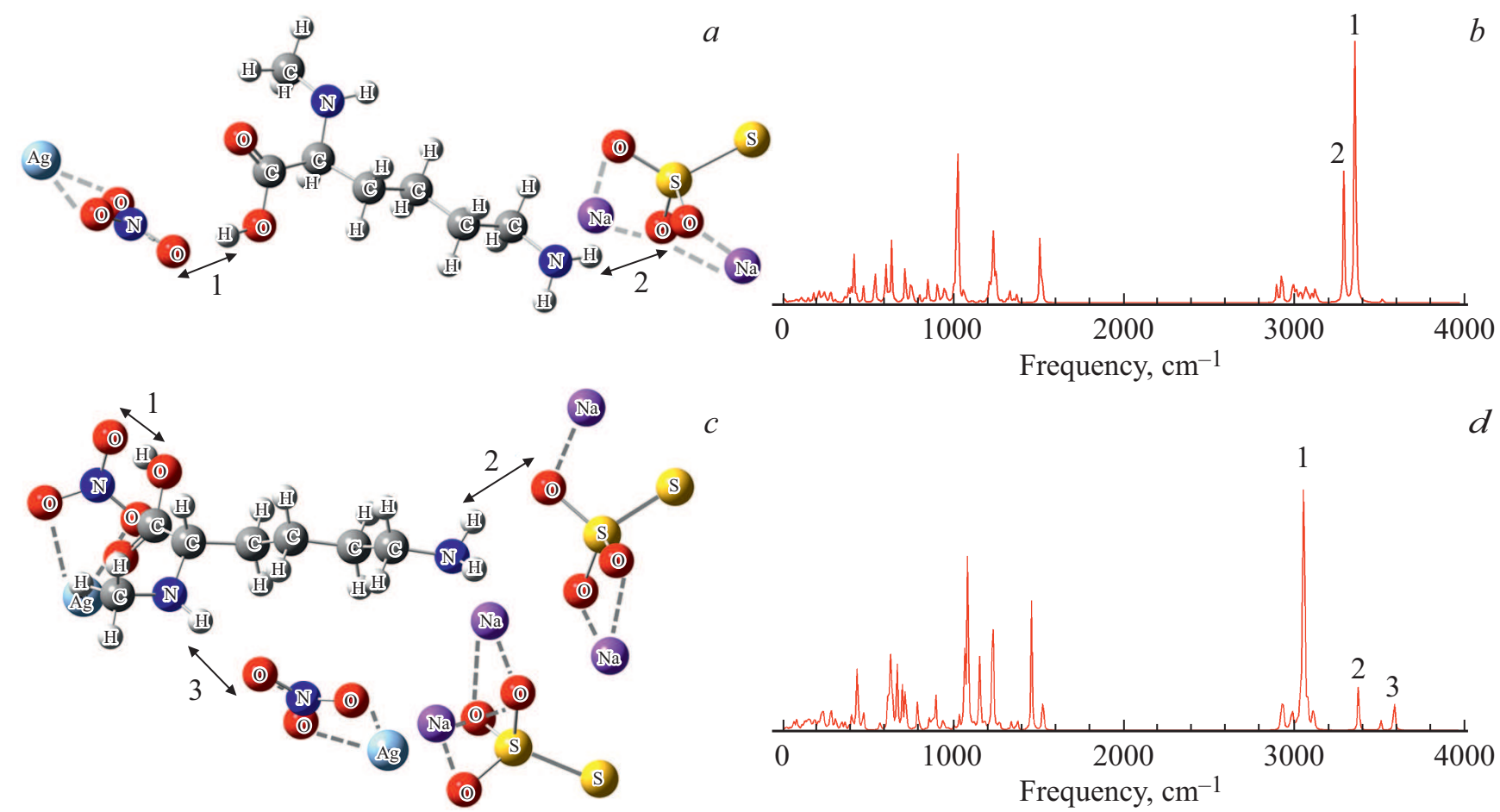

$c$

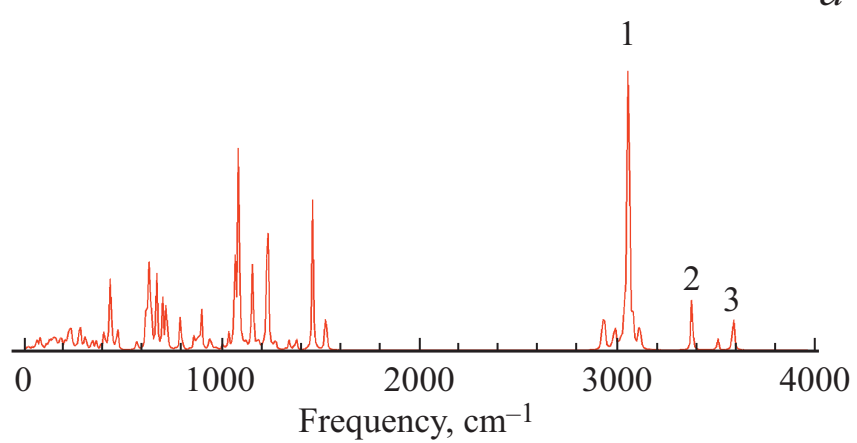

Рис. 7. Рассчитанные структуры $(a, c)$ и ИК спектры $(b, d)$ для молекулярного комплекса метиллизина с нитратом серебра $\mathrm{AgNO}_{3}$ и тиосульфатом натрия $\mathrm{Na}_{2} \mathrm{~S}_{2} \mathrm{O}_{3}$ с одиночными молекулами солей металлов $(a, b)$ и с двумя молекулами каждой из солей металлов $(c, d)$ с обозначенными Н-связями (1-3). 
Таблица 1. Рассчитанные параметры водородных связей для трех вариантов молекулярного комплекса тиосульфат натрия $\mathrm{Na}_{2} \mathrm{~S}_{2} \mathrm{O}_{3}$ - метиллизин

\begin{tabular}{c|c|c|c|c|c|c|c}
\hline $\begin{array}{c}\text { Номер варианта/ } \\
\text { номер связи }\end{array}$ & Тип связи & $\begin{array}{c}\text { Длина } \\
\text { Н-связи } R, \AA\end{array}$ & $\begin{array}{c}\text { Длина } \\
\text { водородного } \\
\text { мостика } R_{b}, \AA\end{array}$ & $\begin{array}{c}\text { Частота } \\
\nu, \mathrm{cm}^{-1}\end{array}$ & $\begin{array}{c}\text { Частотный } \\
\text { сдвиг } \Delta \nu, \mathrm{cm}^{-1}\end{array}$ & $\begin{array}{c}\text { Энергия связи }-\Delta H, \\
\mathrm{kkal} / \mathrm{mol}\end{array}$ & $\begin{array}{c}\text { Интенсивность } \\
I_{\mathrm{IR}}, \mathrm{km} / \mathrm{mol}\end{array}$ \\
\hline $1 / 1$ & $\mathrm{~N}-\mathrm{H} \cdots \mathrm{O}$ & 1.01 & 2.83 & 3388 & 138 & 2.96 & 228 \\
\hline $2 / 1$ & $\mathrm{O}-\mathrm{H} \cdots \mathrm{O}$ & 0.99 & 2.63 & 2896 & 773 & 8.12 & 3956 \\
\hline $3 / 1$ & $\mathrm{~N}-\mathrm{H} \cdots \mathrm{O}$ & 1.02 & 3.01 & 3451 & 67 & 1.55 & 118
\end{tabular}

Таблица 2. Рассчитанные параметры водородных связей для трех вариантов молекулярного комплекса нитрат серебра $\mathrm{AgNO}_{3}-$ метиллизин

\begin{tabular}{c|c|c|c|c|c|c|c}
\hline $\begin{array}{c}\text { Номер варианта/ } \\
\text { номер связи }\end{array}$ & Тип связи & $\begin{array}{c}\text { Длина } \\
\text { Н-связи } R, \AA\end{array}$ & $\begin{array}{c}\text { Длина } \\
\text { водородного } \\
\text { мостика } R_{b}, \AA\end{array}$ & $\begin{array}{c}\text { Частота } \\
\nu, \mathrm{cm}^{-1}\end{array}$ & $\begin{array}{c}\text { Частотный } \\
\text { сдвиг } \Delta v, \mathrm{~cm}^{-1}\end{array}$ & $\begin{array}{c}\text { Энергия связи }-\Delta H, \\
\mathrm{kkal} / \mathrm{mol}\end{array}$ & $\begin{array}{c}\text { Интенсивность } \\
I_{\mathrm{IR}}, \mathrm{km} / \mathrm{mol}\end{array}$ \\
\hline $1 / 1$ & $\mathrm{O}-\mathrm{H} \cdots \mathrm{O}$ & 0.99 & 2.79 & 3406 & 263 & 4.47 & 1312 \\
\hline $2 / 1$ & $\mathrm{~N}-\mathrm{H} \cdots \mathrm{O}$ & 1.01 & 3.15 & 3630 & 104 & 2.4 & 49 \\
\hline $3 / 1$ & $\mathrm{~N}-\mathrm{H} \cdots \mathrm{O}$ & 1.02 & 3.16 & 3603 & 85 & 2.01 & 49
\end{tabular}

Таблица 3. Рассчитанные параметры водородных связей для двух вариантов молекулярного комплекса нитрат серебра $\mathrm{AgNO}_{3}$ - метиллизин-тиосульфат натрия $\mathrm{Na}_{2} \mathrm{~S}_{2} \mathrm{O}_{3}$

\begin{tabular}{|c|c|c|c|c|c|c|c|}
\hline $\begin{array}{c}\text { Номер варианта/ } \\
\text { номер связи }\end{array}$ & Тип связи & $\begin{array}{c}\text { Длина } \\
\text { Н-связи } R, \AA\end{array}$ & $\begin{array}{c}\text { Длина } \\
\text { водородного } \\
\text { мостика } R_{b}, \AA\end{array}$ & $\begin{array}{l}\text { Частота } \\
v, \mathrm{~cm}^{-1}\end{array}$ & $\begin{array}{c}\text { Частотный } \\
\text { сдвиг } \Delta v, \mathrm{~cm}^{-1}\end{array}$ & $\begin{array}{c}\text { Энергия связи }-\Delta H, \\
\mathrm{kkal} / \mathrm{mol}\end{array}$ & $\begin{array}{c}\text { Интенсивность } \\
I_{\mathrm{IR}}, \mathrm{km} / \mathrm{mol}\end{array}$ \\
\hline $1 / 1$ & $\mathrm{O}-4 \mathrm{H} \cdots \mathrm{O}$ & 0.99 & 2.77 & 3353 & 316 & 4.98 & 1265 \\
\hline $1 / 2$ & $\mathrm{~N}-\mathrm{H} \cdots \mathrm{O}$ & 1.01 & 3.03 & 3290 & 228 & 4.11 & 442 \\
\hline $2 / 1$ & $\mathrm{O}-\mathrm{H} \cdots \mathrm{O}$ & 0.99 & 2.70 & 3057 & 612 & 7.17 & 1462 \\
\hline $2 / 2$ & $\mathrm{~N}-\mathrm{H} \cdots \mathrm{O}$ & 1.01 & 2.94 & 3380 & 146 & 3.08 & 172 \\
\hline $2 / 3$ & $\mathrm{~N}-\mathrm{H} \cdots \mathrm{O}$ & 1.02 & 3.11 & 3594 & 76 & 1.79 & 138 \\
\hline
\end{tabular}

вариантов приведены в табл. 1 и 2. Видно, что не все варианты являются равноценными. Для тиосульфата натрия $\mathrm{Na}_{2} \mathrm{~S}_{2} \mathrm{O}_{3}$ были рассмотрены три варианта комплексообразования, в двух из которых образуются водородные связи средней силы (варианты 1 и 2).

Структура и ИК спектры для этих двух вариантов показаны на рис. 5, а параметры водородных связей указаны в табл. 1. В третьем варианте образуется слабая водородная связь (параметры связи этого варианта также указаны в табл. 1). Наиболее сильной является водородная связь О-Н... О (вариант 2). Частота валентных колебаний связи О-Н в этом случае составляет $v=2896 \mathrm{~cm}^{-1}$ (рис. 5, $c, d$, вариант 2).

При образовании этой водородной связи наблюдается частотный сдвиг в длинноволновую область $\Delta v=773 \mathrm{~cm}^{-1}$, при этом длина образовавшегося водородного мостика составляет $2.63 \AA$, интен- сивность образовавшегося пика достаточно высока: $I_{\mathrm{IR}}=3956 \mathrm{~km} / \mathrm{mol}$, а энергия данной водородной связи $-\Delta H=8.12 \mathrm{kcal} / \mathrm{mol}$, что соответствует средней водородной связи, приближающейся к сильной, и говорит о стабильности образующейся молекулярной структуры.

При анализе водородных связей в комплексообразовании молекул метиллизина с нитратом серебра $\mathrm{AgNO}_{3}$ также были рассмотрены три варианта присоединения (рис. 6, табл. 2). Необходимо отметить, что наиболее сильное взаимодействие наблюдается в случае присоединения через группу О-H (вариант 1), как и для тиосульфата натрия. При образовании водородной связи $\mathrm{O}-\mathrm{H} \cdots \mathrm{O}$ наблюдается частотный сдвиг в длинноволновую область $\Delta v=263 \mathrm{~cm}^{-1}$, при этом интенсивность пика $I_{\mathrm{IR}}=1312 \mathrm{~km} / \mathrm{mol}$, а энергия образовавшейся водородной связи $-\Delta H=4.37 \mathrm{kcal} / \mathrm{mol}$, что соответствует средней водородной связи. 
Поскольку в экспериментальных работах $[6,7]$ по биосинтезу наночастиц сульфида серебра, синтезированных с помощью Bacillus subtilis 16, в качестве рабочего раствора использовалась смесь солей нитрата серебра и тиосульфата натрия (как отмечается в [7], „биосинтез наночастиц $\mathrm{Ag}_{2} \mathrm{~S}$ проводили в $1 \mathrm{MM}$ водном растворе солей $\mathrm{AgNO}_{3}$ и $\mathrm{Na}_{2} \mathrm{~S}_{2} \mathrm{O}_{3} \cdot 5 \mathrm{H}_{2} \mathrm{O}$ в присутствии клеток бактерий в аэробных условия ““), то в ходе исследования нами была рассмотрена возможность образования молекулярного комплекса в трехкомпонентной смеси метиллизина с обеими солями одновременно.

На рис. $7, a, b$ показан один из примеров такого комплексообразования: структура и ИК спектр молекулярного комплекса нитрат серебра $\mathrm{AgNO}_{3}$-метиллизин-тиосульфат натрия $\mathrm{Na}_{2} \mathrm{~S}_{2} \mathrm{O}_{3}$. Видно, что с каждой солью метиллизин образует водородную связь средней силы. Параметры связей указаны в табл. 3. Видно, что и в том, и в другом случаях возникают водородные связи средней силы: наблюдаются частотные сдвиги $\Delta v_{1}=316 \mathrm{~cm}^{-1}$ и $\Delta v_{2}=228 \mathrm{~cm}^{-1}$, энергия водородных связей составляет $-\Delta H=4.98 \mathrm{kcal} / \mathrm{mol}$ и $-\Delta H=4.11 \mathrm{kcal} / \mathrm{mol}$ соответственно.

Также были рассчитаны структуры, ИК спектры и параметры водородных связей четырехкомпонентных смесей, где к метиллизину присоединяется две молекулы $\mathrm{AgNO}_{3}$ и одна $\mathrm{Na}_{2} \mathrm{~S}_{2} \mathrm{O}_{3}$. Структура и ИК спектр такого комплекса показаны на рис. $7, c, d$. Как и в предыдущем примере, наиболее сильной является связь $\mathrm{O}-\mathrm{H} \cdots \mathrm{O}-$ частотный сдвиг достаточно большой: $\Delta v_{1}=612 \mathrm{~cm}^{-1}$, а энергия водородной связи $-\Delta H=7.17 \mathrm{kcal} / \mathrm{mol}$ (табл. 3). Связи $\mathrm{N}-\mathrm{H} \cdots \mathrm{O}$ являются средними, близкими к слабым и слабыми.

Данные примеры являются одними из нескольких возможных подобных трех-, четырех- и пятикомпонентных молекулярных комплексов, где сила образующихся водородных связей, как правило, является средней.

\section{Выводы}

На основе результатов молекулярного моделирования различных вариантов комплексообразования метиллизина с солями нитрата серебра $\mathrm{AgNO}_{3}$ и тиосульфата натрия $\mathrm{Na}_{2} \mathrm{~S}_{2} \mathrm{O}_{3}$ и последующего анализа параметров образующихся связей была установлена возможность образования нескольких водородных связей средней силы с энергиями от 2.96 до $8.12 \mathrm{kcal} / \mathrm{mol}$ как при двойном, так и при тройном комплексообразовании. Кроме того, необходимо отметить особое влияние процесса метилизации лизина, способствующее образованию более прочной органической оболочки синтезируемых наночастиц.

Таким образом, можно сделать вывод о том, что метиллизин образует достаточно устойчивые молекулярные комплексы с тиосульфатом натрия и нитратом серебра, что дает возможность говорить о его существенном вкладе в процесс образования наночастиц сульфида серебра методом биосинтеза с помощью грамположительных бактерий Bacillus subtilis 168. Более прочная и объемная органическая оболочка наночастиц, получаемая в результате синтеза с помощью Bacillus subtilis 168, практически одинаковые размеры получаемых наночастиц (около $10 \mathrm{~nm}$ ) свидетельствуют о том, что синтез на основе именно этих бактерий является одним из перспективных методов бактериального синтеза наночастиц сульфида серебра. Также необходимо отметить особую роль метиллизина при межмолекулярном взаимодействии в составе флагеллина, что данное исследование отчасти подтверждает.

\section{Благодарности}

Авторы работы выражают благодарность главному научному сотруднику лаборатории белковой инженерии ФГБУ „Государственный научно-исследовательский институт генетики и селекции промышленных микроорганизмов Национального исследовательского центра „Курчатовский институт ““ Т.А. Воейковой за предложение интересной и перспективной задачи, имеющей большое практическое значение для биофизики.

\section{Финансирование работы}

Работа поддержана грантом Российского фонда фундаментальных исследований № 20-33-90250/20.

\section{Конфликт интересов}

Авторы заявляют, что у них нет конфликта интересов.

\section{Список литературы}

[1] Деев С.М., Лебеденко Е.Н. //Молекулярная биология. 2017. T. 51. № 6. C. 907. doi 10.7868/S0026898417060040

[2] Бражник К.И., Барышникова М.А., Соколова З.А., Набиев И.Р., Суханова А.В. // Российский биотерапевтический журн. 2013. Т. 12. № 3. С. 12.

[3] Dolez P.I. Nanomaterials. Definition, Classification and Application in Nanoengineering: Global Approaches to Health and Safety Issues. Amsterdam: Elsevier, 2015. P. 3.

[4] Bouccara S., Sitbon G., Fragola A., Lorette V., Lequeny N., Pons T. // Current Opinion in Biotechnology. 2015. V. 34. P. 65. doi 10.1016/j.copbio.2014.11.018

[5] Билан Р.С., Бражсник К.И., Шамс П., Бати Д., Набиев И.Р., Суханова А.В. // Российский биотерапевтический журн. 2014. Т. 14. № 4. С. 11.

[6] Журавлева О.А., Воейкова Т.А., Кедик С.А., Грищкова И.А., Гусев С.А., Ретивов В.М., Кожухова Е.И., Дебабов В.Г. // Тонкие химические технологии. 2019. Т. 14. № 3. С. 50. doi 10.32362/2410-6593-2019-14-3-50-59

[7] Воейкова Т.А., Журавлева О.А., Булушова Н.В., Вейко В.П., Исмагулова Т.Т., Лупанова Т.Н., Шайтан К.В., Дебабов В.Г. // Молекулярная генетика, микробиология, вирусология. 2017. Т. 35. № 4. С. 151. doi 10.18821/02080613-2017-35-4-151-156 
[8] Метлина А.Л. //Успехи биологической химии. 2001. Т. 41. C. 229.

[9] RCSB Protein Data Bank. [Электронный pecypc] Режим доступа: https://www.rcsb.org/3d-view/6GOW doi $10.2210 / \mathrm{pdb} 6 \mathrm{GOW} / \mathrm{pdb}$

[10] Delange R.J., Chang J.Y., Shaper J.H., Glaser A.N. // J. Biological Chemistry. 1976. V. 251. N 3. P. 705.

[11] Leninger A.L. Principles of Biochemistry. Published by Worth Publishers, Inc. 1982; Ленинджер А. Основы биохимии: в 3-х т. Т. 1. Пер. с англ. М.: Мир, 1985. 367 с.

[12] Plastun I.L., Bokarev A.N., Zakharov A.A., Naumov A.A. // Fullerenes, Nanotubes and Carbon Nanostructures. 2020. V. 28. N 3. P.1 83. doi 10.1080/1536383X.2019.1686618

[13] Kohn W. // Rev. Mod. Phys. 1999. V. 71. N 5. P. 1253; Кон В. // Успехи физ. наук. 2002. Т. 172. № 3. С. 336. doi 10.1103/RevModPhys.71.1253

[14] Becke A.D. // J. Chem. Phys. 1993. V. 98. N 7. P. 5648. doi $10.1063 / 1.464913$

[15] Frisch M.J., Trucks G.W., Cheeseman J.R., Scalmani G., Caricato M., Hratchian H.P., Li X., Barone V., Bloino J., Zheng G. et al. Gaussian 09, Revision A.02. Wallingford CT: Gaussian Inc., 2009.

[16] Chiodo S., Russo N., Sicilia E. // J. Chem. Phys. 2006. V. 125. N 10. P. 104107. doi 10.1063/1.2345197

[17] Электронный ресурс. Режим доступа: https://spectrabase. com/spectrum/7ROZTVrsbdM

[18] Электронный ресурс. Режим доступа: https://spectrabase. com/spectrum/8u $9 \mathrm{~s} 5$ tkSShZ

[19] Rogachev A.A., Yarmolenko M.A., Rogachou A.V., Tapalski D.V., Liu X., Gorbachev D.L. // RSC Advances. 2013. V. 3. P. 11226 . doi $10.1039 / \mathrm{c} 3 \mathrm{ra} 23284 \mathrm{k}$

[20] Электронный ресурс. Режим доступа: https://spectrabase. com $/$ spectrum $/ 7 \mathrm{kr} 7 \mathrm{mSoNW0L}$

[21] Carneiro J., Döll-Boscardin P.M., Fiorin B.C., Nadal J.M., Farago P.V., de Paula J.P. // Brazilian J. Pharmaceutical Sciences. 2016. V. 52. N 4. P. 645. doi 10.1590/S198482502016000400008

[22] Бабков Л.М., Пучковская Г.А., Макаренко С.П., Гаврилко T.A. ИК спектроскопия молекулярных кристаллов с водородными связями. Киев: Наукова думка, 1989. 160 с.

[23] Jeffrey G.A. An Introduction to Hydrogen Bonding. NY: Oxford University press, 1997. 303 p.

[24] Стид Джс.В., Этвуд Джк.Л. Супрамолекулярная химия. T. 1. М.: Академкнига, 2007. 479 с. 